\title{
ESCÓRIA DE SIDERURGIA E CALCÁRIO NA TAXA DE FOLHAS SENESCENTES DA CULTURA DA CANA-DE-AÇÚCAR
}

\author{
Renato de Mello Prado ${ }^{1}$ \\ Francisco Maximino Fernandes ${ }^{2}$
}

\section{RESUMO}

Por avaliar o efeito da escória de siderurgia, comparado ao do calcário, na taxa de folhas senescentes na cultura da cana-de-açúcar, instalou-se um experimento em casa-de-vegetação. Usou-se um fatorial de 2 Corretivos (Calçario e Escória) x 2 Níveis de Aplicação (nível $1=$ dose para obter $\mathrm{V}=50 \%$, e nível 2 , o dobro dessa dose), inteiramente casualizado, com 4 repetições, em 2 tipos de solo: Latossolo VermelhoEscuro e Areia Quartzosa. Concluiu-se que o uso da escória, em lugar do calcário, traz redução da taxa de senescência de folhas da cana-de-açúcar. A dose menor foi suficiente em ambos os solos estudados.

Palavras-chave: escória de siderurgia, silício, folha, senescência, Saccharum spp.

\section{ABSTRACT}

\section{EFFECT OF SLAG AND LIMESTONE ON THE PERCENTAGE OF SENESCENT LEAVES IN SUGAR CANE}

Two experiments completely randomized, carried out in greenhouse, were a 2 Corrective Agents (Siderurgical Slag and Limestone)

${ }^{1}$ Doutorando em Ciência do Solo, Fac. de Ciências Agrárias e Veterinárias, UNESP, Via de Acesso Prof. Paulo Donato Castallane, s/n, CEP 14870-000, Jaboticabal-SP, Brasil. E-mail <rmprado@fcav.unesp.br>. Bolsista da Fapesp.

${ }^{2}$ Dep. de Ciência do Solo e Engenharia Rural, Faculdade de Engenharia de Ilha Solteira, UNESP, Caixa Postal 31, CEP 15385-000, Ilha Solteira-SP, Brasil. 
$\times 2$ Levels of Application (level 1 = quantity needed to obtain $\mathrm{V}=50 \%$, level 2 = double of level 1) factorial, with 4 replicates, both on a Dark Red Latosol and a Quartzose Sand. Conclusion is that siderurgical slag applied to sugar cane crop, instead of limestone, reduces the percentage of senescent leaves from $34.5 \%$ down to $28.4 \%$, on the average. Level 1 is enough to carry out this reduction.

Key words: slag, silicon, leaves, senescence, Saccharum spp.

\section{INTRODUÇÃO}

A região Centro Sul do Brasil possui importante pólo siderúrgico, com produção de aço, ferro-gusa e, como resíduo, escória de siderurgia. $\mathrm{Na}$ mesma região se concentra a maior área agrícola com a cultura da cana-de-açúcar, o que coloca o Brasil como o maior produtor e exportador de açúcar do mundo. Dentre os Estados da federação, São Paulo destaca-se com área de 2,493 milhões de ha., com produção de colmos de 192,32 mil toneladas, e rendimento médio de 77,14 t ha ${ }^{-1}$ (Anuário Estatístico do Brasil, 1997).

Como a cana-de-açúcar é cultura pioneira e a mais efetiva na reciclagem resíduos agroindustriais, a exemplo da vinhaça e da torta de filtro, pode, da mesma forma, reciclar resíduos das indústrias siderúrgicas, reduzindo seus impactos ambientais em torno das siderúrgicas.

Os primeiros trabalhos no Brasil com uso agronômico das escórias de siderurgia ocorreram em culturas anuais, como sorgo, milho e soja. O uso agronômico e a maioria das pesquisas com a escória de siderurgia, especificamente na cana-de-açúcar, começaram em 1966. Apenas na década de 90 foram intensificados os trabalhos, na região da Flórida, Estados Unidos. No Brasil, recentemente, foram conduzidos experimentos com a escória de siderurgia na cultura da cana-de-açúcar, atestando seu efeito nos atributos químicos do solo, como aumento no teor de P disponível (Prado \& Fernandes, 1999), na correção da acidez do solo (Prado, 
2000) e com respostas positivas na produção de matéria seca e no perfilhamento da cana-de-açúcar (Prado \& Fernandes, 2000).

Além destes efeitos, a escória de siderurgia pode aumentar o teor de silício do solo, em razão da sua constituição química, a base de silicato de cálcio (Prado, 1998). Apesar de o silício não ser considerado nutriente, é elemento benéfico, especialmente para culturas acumuladoras como arroz e cana-de-açúcar, que apresentam teor de Si igual ou até maior que o do N (Epstein, 1995). Ultimamente tem sido estudado o efeito fisiológico do Si na planta. Neste sentido, alguns autores têm atribuído ao silício a prevenção do progresso da senescência foliar nas culturas do arroz (Agarie et al.,1998a) e do pepino (Adatia \& Besford, 1986) devido à manutenção da fotossíntese e proteção da clorofila, especialmente em condições de altas temperaturas e baixa umidade. Este efeito pode ser explicado em razão de estar o silício ligado à estabilidade térmica dos lipídeos nas membranas celulares em condições de estresse ambiental. $O$ Si previne a deterioração estrutural e funcional das membranas celulares no arroz, e isto poderia contribuir para a prevenção do processo de envelhecimento da folha (Agarie et al., 1998b).

O presente trabalho objetivou avaliar o efeito da escória de siderurgia, comparada ao calcário, na taxa de folhas senescentes da cultura da cana-de-açúcar.

\section{MATERIAL E MÉTODOS}

O experimento, conduzido em casa de vegetação no período de Julho de 1997 a setembro de 1998, utilizou vasos com $20 \mathrm{dm}^{3}$ de solo.

Inicialmente foram coletadas amostras da camada superficial (0 a $20 \mathrm{~cm})$ de dois solos, ambos sob vegetação natural de cerrado, Latossolo Vermelho-Escuro (LE), álico, textura argilosa, da Fazenda de Ensino e Pesquisa da UNESP, município de Selvíria, MS, e Areia Quartzosa (AQ), álica, textura arenosa, localizada na Fazenda Horto Barra da Moeda, município de Três Lagoas-MS. 
Os solos coletados foram secados e peneirados, utilizando peneira com malha de $4 \mathrm{~mm}$. Foi realizada a análise química dos solos conforme metodologia de Raij \& Quaggio (1983), cujos resultados estão apresentados na Tabela 1.

Tabela 1. Análise química e física do Latossolo Vermelho-Escuro (LE) e da Areia Quartzosa (AQ) utilizados no experimento (camada de 0 a $20 \mathrm{~cm}$ de profundidade).

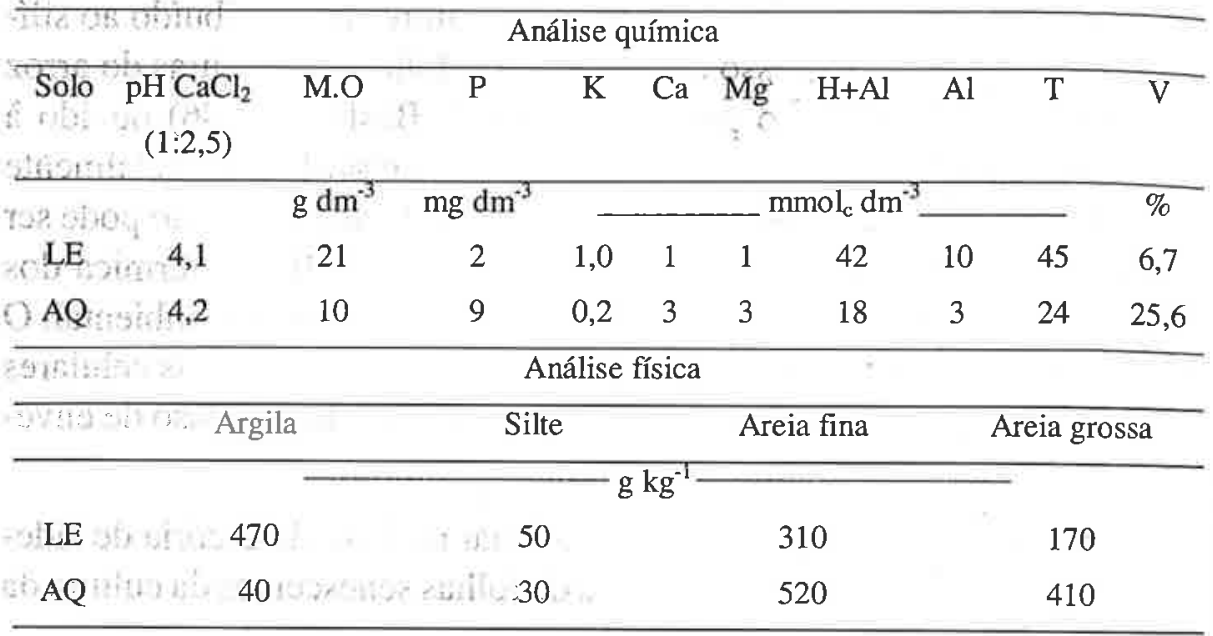

Foi utilizada a escória de siderurgia de alto forno proveniente da siderúrgica Cossisa de Sete Lagoas, MG, produtora de ferro-gusa. Esta por sua vez foi seca em estufa a $60^{\circ} \mathrm{C}$ e posteriormente moída e passada numa peneira com malha de $0 ; 297 \mathrm{~mm}$ de abertura (ABNT n ${ }^{\circ} .50$ ). O calcário calcítico utilizado foi passado na mesma peneira. Deste modo, ambos os corretivos apresentavam granulometrias semelhantes e reatividade (RE) igual a $100 \%$. Em seguida foi realizada análise química, expresso em \% na escória: $\mathrm{PN}=60,9(\mathrm{CaO}=30,2$ e $\mathrm{MgO}=2,8)$ e $\mathrm{PRNT}=60,9$ (Alcarde \& Rodella, 1996); $\mathrm{SiO}_{2}$ total $=39,9$ e a relação de alcalinidade Eq. $\mathrm{CaO} / \mathrm{SiO}_{2}$ (Eq.CaO: equivalente de $\mathrm{Ca}$ e $\mathrm{Mg}$ expresso em $\mathrm{CaO}$ ) $=0,85$ e no calcário expresso em \%: $\mathrm{PN}=79,5(\mathrm{CaO}=39,5$ e $\mathrm{MgO}=3,5), \mathrm{PRNT}=79,5$ o $\mathrm{Ca}=28,26 ; \mathrm{Mg}=2,12$. 
Usou-se um fatorial de 2 Corretivos (Calcário e Escória) $\times 2$ Níveis de Aplicação (nível 1 = dose para obter $\mathrm{V}=50 \%$, e nível $2=$ o dobro dessa dose); inteiramente casualizado, com 4 repetições, em 2 tipos de solo (Latossolo Vermelho-Escuro e Areia Quartzosa), em casa-de-vegetação.

Tabela 2. Quantidades de escória de siderurgia e calcário, aplicadas no Latossolo Vermelho-Escuro (LE) e na Areia Quartzosa (AQ) utilizados no experimento.

\begin{tabular}{|c|c|c|c|c|c|}
\hline Solo & Níveis de Aplicação & & & $\mathrm{Cal}$ & \\
\hline \multirow{3}{*}{ LE } & & g por vaso & $\mathrm{tha}^{-1}$ & g por vaso & $\mathrm{tha}^{-1}$ \\
\hline & $1^{(1)}$ & 31,2 & 3,12 & 23,9 & 2,39 \\
\hline & 2 & 62,4 & 6,24 & 47,8 & 4,78 \\
\hline \multirow[b]{2}{*}{$\mathrm{AQ}$} & 1 & 11,1 & 1,11 & 8,5 & 0,85 \\
\hline & 2 & 22,2 & 2,22 & 17,0 & 1,70 \\
\hline
\end{tabular}

(1) 1 = calcário ou escória aplicado na dose para elevar V =50\%, e 2= calcário ou escória aplicado, correspondente ao dobro da dose menor.

Após a aplicação dos corretivos, os solos foram incubados por 30 dias, com umidade próxima de $70 \%$ da capacidade de retenção de água (CRA). Portanto a CRA para o LE e AQ foi de 27,38 e $16,88 \%$, respectivamente.

Decorrido o período de incubação, cultivou-se a cana-de-açúcar (variedade RB 72454). A adubação básica em todos os vasos foi constituída de: $210 \mathrm{mg} \mathrm{dm}^{-3} \mathrm{de} \mathrm{N}$ (sulfato de amônio), sendo $30 \mathrm{mg} \mathrm{dm}^{-3}$ no plantio e o restante parcelado em quatro vezes : 30, 75,120 e 150 dias após a emergência do broto; $200 \mathrm{mg} \mathrm{dm}^{-3}$ de $\mathrm{P}$ (superfosfato triplo) no plantio; $220 \mathrm{mg} \mathrm{dm}^{-3}$ de $\mathrm{K}$ (cloreto de potássio), sendo $60 \mathrm{mg} \mathrm{dm}^{-3}$ no 
plantio e o restante parcelado em quatro vezes: 30,75,120 e 150 dias após a emergência do broto. Em seguida, realizou-se o plantio deixando 2 plantas uniformes em cada vaso. A irrigação realizada manteve a umidade ao redor de $70 \%$ da CRA, para os dois solos, durante os dois cultivos, através de pesagens diárias dos vasos, que tinham o fundo furado.

Após período do cultivo da cana-de-açúcar (210 dias após a emergência do broto), determinou-se a porcentagem de folhas senescentes (100 $\mathrm{x}$ número de folhas senescentes/número total de folhas da planta). Estes dados foram levantados para as duas classes de solo em estudo.

Os resultados obtidos foram submetidos a análise de variância associada ao teste $\mathrm{F}$, ao nível de $5 \%$ de probabilidade.

\section{RESULTADOS E DISCUSSÃO}

Para o Latossolo Vermelho-Escuro, a análise da variância (Tabela 3) comprovou efeito de Corretivos, mas não foi significativo para Níveis de Aplicação; nem para a Interação Corretivos x Níveis de Aplicação. As médias dos Tratamentos (Tabela 4 ) mostram redução de $35,6 \%$ para $26,9 \%$ na senescência de folhas, com aplicação de Escória em lugar de Calcário. Este resultado está de acordo com Agarie et al. (1998 a,b), para quem o silício da Escória prolonga a vida útil da folha, pela redução da sua taxa de senescência.

Após a aplicação dos corretivos, os solos foram incubados por 30 dias, com umidade próxima de $70 \%$ da capacidade de retenção de água (CRA). Portanto a CRA para o LE e AQ foi de 27,38 e $16,88 \%$, respectivamente.

Decorrido o período de incubação, cultivou-se a cana-de-açúcar (variedade RB 72454). A adubação básica em todos os vasos foi constituída de: $210 \mathrm{mg} \mathrm{dm}^{-3}$ de $\mathrm{N}$ (sulfato de amônio), sendo $30 \mathrm{mg} \mathrm{dm}^{-3}$ no plantio e o restante parcelado em quatro vezes : 30, 75,120 e 150 dias após a emergência do broto; $200 \mathrm{mg} \mathrm{dm}^{-3}$ de $\mathrm{P}$ (superfosfato triplo) no 
Tabela 3. Análise de variância dos fatores Corretivos e Níveis de Aplicação para a taxa de folhas senescentes, no solo LE. Ilha Solteira-SP, 1998.

\begin{tabular}{cccc}
\hline Causa de variação & GL & QM & F \\
\hline Corretivo (C) & 1 & 304,502 & $5,939^{*}$ \\
Níveis de Aplicação (NA) & 1 & 102,010 & $1,990^{\mathrm{NS}}$ \\
C x NA & 1 & 18,922 & $0,370^{\mathrm{NS}}$ \\
(Tratamentos) & 3 & $(141,812)$ & $\left(2,766^{*}\right)$ \\
Resíduo & 12 & 51,268 &
\end{tabular}

$(* ;$ NS :significativo $(\mathrm{P}<0,05)$ e não significativo $(\mathrm{P}>0,05)$ respectivamente pelo teste de $\mathrm{F}$.

Tabela 4. Efeito dos corretivos e dos níveis de aplicação sobre a taxa de folhas senescentes da cultura da cana-de-açúcar, cultivada em Latossolo Vermelho-Escuro

Taxa de folhas senescentes (\%)

\begin{tabular}{ll}
\hline \multicolumn{1}{c}{ Corretivo } \\
\hline Calcário & $35,6 \mathrm{a}$ \\
Escória & $26,9 \mathrm{~b}$ \\
\hline \multicolumn{2}{c}{ Níveis de Aplicação } \\
\hline NA1 & $33,7 \mathrm{a}$ \\
NA2 & $28,7 \mathrm{a}$ \\
\hline
\end{tabular}

Letras diferentes indicam diferença significativa ao nível de $5 \%$. 
Tabela 5. Análise de variância dos fatores corretivos e níveis de aplicação para a taxa de folhas senescentes, no solo AQ. Ilha Solteira-SP, 1998.

\begin{tabular}{cccc}
\hline Causa de variação & GL & QM & F \\
\hline Corretivo (C) & 1 & 148,840 & $15,318^{* *}$ \\
Níveis de Aplicação (NA) & 1 & 29,160 & $3,001^{\mathrm{NS}}$ \\
C x N A & 1 & 30,250 & $3,113^{\mathrm{NS}}$ \\
(Tratamentos) & $(3)$ & $(69,417)$ & $\left(7,144^{* *}\right)$ \\
Resíduo & 12 & 9,717 & \\
\hline M édia geral: 31,43\% & CV: $9,9 \%$ & \\
**:Ns :significativo (P<0,01) e não significativo (P>0,05) respectivamente pelo teste de F.
\end{tabular}

plantio; $220 \mathrm{mg} \mathrm{dm}^{-3}$ de $\mathrm{K}$ (cloreto de potássio), sendo $60 \mathrm{mg} \mathrm{dm}^{-3}$ no plantio e o restante parcelado em quatro vezes: 30,75,120 e 150 dias após a emergência do broto. Em seguida, realizou-se o plantio deixando 2 plantas uniformes em cada vaso. A irrigação realizada manteve a umidade ao redor de $70 \%$ da CRA, para os dois solos, durante os dois cultivos, através de pesagens diárias dos vasos, que tinham o fundo furado.

Após período do cultivo da cana-de-açúcar (210 dias após a emergência do broto), determinou-se a porcentagem de folhas senescentes (100 $\mathrm{x}$ número de folhas senescentes/número total de folhas da planta). Estes dados foram levantados para as duas classes de solo em estudo.

Os resultados obtidos foram submetidos a análise de variância associada ao teste $\mathrm{F}$, ao nível de $5 \%$ de probabilidade.

No caso da Areia Quartzosa aconteceu fato semelhante (Tabelas 4 e 5): foi significativa a diferença entre Corretivos, mas para Níveis de Aplicação e para a Interação Corretivos x Níveis de Aplicação o efeito não foi comprovado. E a Escória novamente reduziu significativamente a senescência das folhas, o que aumenta sua vida útil. 
Tabela 6. Efeito dos corretivos e dos níveis de aplicação sobre a taxa de folhas senescentes da cultura da cana-de-açúcar, em Areia Quartzosa.

\begin{tabular}{lc}
\hline \multicolumn{1}{c}{ Corretivo } & Taxa de folhas senescentes (\%) \\
\hline Calcário & $34,48 \mathrm{a}$ \\
Escória & $28,38 \mathrm{~b}$ \\
\hline \multicolumn{2}{c}{ Níveis de Aplicação } \\
\hline NA1 & $32,78 \mathrm{a}$ \\
NA2 & $30,08 \mathrm{a}$ \\
\hline
\end{tabular}

Letras diferentes indicam diferença significativa ao nível de $5 \%$.

A cana-de-açúcar, planta do tipo $\mathrm{C} 4$, é caracterizada pela grander capacidade de produção de matéria orgânica, em razão da alta taxa de fotossíntese por unidade de área de terreno, influenciada diretamente pelo: índice de área foliar (Magalhães, 1987). E o uso da escória de siderurgia na cana-de-açúcar pode incrementar ainda mais a taxa de fotossíntese! em razão da redução da senescência foliar que prolonga a vida útil da. folha, e pode trazer reflexos na produtividade da cultura. Haja vista que Agarie et al. (1992) informam que a manutenção da atividade fotossíntética é considerada a principal razão do incremento da matéria seca da planta em resultado da aplicação do silício. Portanto, o fato de o uso da escória de siderurgia aumentar a vida 'ítil da folha é uma vantagem adicional ao seu uso, além das já conhecidas, o que pode resultar em maior longevidade do canavial, característica esta, buscada pelos pesquisadores e produtores que trabalham com a cultura.

Como não houve diferença entre os níveis de aplicação para os dois solos em estudo, a dose menor (metade da dose maior) deve ser a preferida por trazer menor custo de aquisição e de transporte dos produtos. 


\section{CONCLUSÕES}

O uso da escória de siderurgia, em substituição ao calcário, traz redução na taxa de senescência de folhas de cana-de-açúcar. A dose:necessária para obter $\mathrm{V}=50 \%$ é suficiente, tanto para Latossolo VermelhoEscuro como para Areia Quartzosa.

\section{REFERÊNCIAS BIBLIOGRÁFICAS}

ADATIA, M.H. \& R.T. BESFORD., 1986. The Effects of Silicon on Cucumber Plants Grown in Recirculating Nutrient Solution. Annals of Botany, 58: 343-351.

AGARIE, S., W. AGATA, F. KUBOTA \& P.B. KAUFFMANN., 1992. Physiological Roles of Silicon in Photosyntesis and Dry Matter Production in Rice Plants. 5 . Effects of Silicon and Shading Treatments. Japanese Journal of Crop Science, 61 (2):200-206. AGARIE, S., W. AGATA \& P.B. KAUFMAN. 1998a. Involvement of Silicon in the Senescence of Rice Leaves. Plant Prod.Sci.,1(2): 104-105. AGARIE, S., N. HANAOKA, O.UENO, A.MIYAZAKI, F. KUBOTA, W. AGATA \& P.B. KAUFFMANN., 1998b. Effects of Silicorí on Tolerance to Water Deficit and Heat Stress in Rice Plants (Orysae sativa L.) monitored by electrolyte leakage. Plant Prod. Sci., 1 (2): 96-103.

ALCARDE, J.C. \& A.A.RODELLA., 1996. Avaliação Química de Corretivos de Acidez para Fins' Agrícolas: Uma Nova Proposição. Scientia Agricola, Piracicaba, 53 (2/3): 211-216.

EPSTEIN, E., 1995. Photosynthesis, Inorganic Plant Nutrition, Solution, and Problems. Photosynthesis Research, 46: 37-39.

MAGALHÃES, A.C.N., 1987. Ecofisiologia da Cana-de-Açúcar: Aspectos do Metabolismo do Carbono na Planta. In: CASTRO, P.R.C., S.O. FERREIRA \& T. YAMADA.(Eds.). Ecofisiologia da Produção Agrícola. Piracicaba, Potafós, p.113-118. 
PRADO, R.M., 1998. Efeito da Escória de Siderurgia nos Atributos Químicos do Latossolo Vermelho Amarelo e na Cultura do Milho. In: CONGRESSO NACIONAL DE MILHO E SORGO, 22., Recife, 1998. Resumos expandidos (CD). Recife, Empresa Pernambucana de Pesquisa Agrícola, EMBRAPA Milho e Sorgo.

PRADO, R.M., 2000. Resposta da Cultura da Cana-de-Açúcar à Aplicação de Escória Silicatada como Corretivo de Acidez do Solo. Ilha Solteira, 97p. (Mestrado em Sistema de Produção pela Faculdade de Engenharia de Ilha Solteira, UNESP).

PRADO, R.M. \& F.M. FERNANDES., 1999. Efeito do Calcário e da Escória de Siderurgia na Disponibilidade de Fósforo no Latossolo Vermelho-Escuro e na Areia Quartzosa. Revista de Agricultura, 74 (2): 235-242.

PRADO, R.M. \& F.M. FERNANDES., 2000. Eficiência da Escória de Siderurgia em Areia Quartzosa na Nutrição e na Produção de Matéria Seca de Cana-de-Açúcar Cultivada em Vaso. STAB Açúcar, Álcool e Subprodutos, 18 (4): 36-39.

RAIJ, B. van. \& J.A.QUAGGIO., 1983. Métodos de análise de solos para fins de fertilidade. Campinas: Instituto Agronômico, 52p. (Boletim Técnico 81). 